\title{
Voltage-Gated Potassium Currents in Cultured Ovine Oligodendrocytes
}

\author{
Betty Soliven, Sara Szuchet, Barry G. W. Arnason, and Deborah J. Nelson \\ Departments of Neurology and Medicine, Brain Research Institute, University of Chicago, Chicago, Illinois 60637
}

\begin{abstract}
Cultured oligodendrocytes (OLGs) develop processes and form myelin following attachment to a substratum. We applied the whole-cell voltage-clamp technique to identify and characterize the ionic currents of OLGs in culture. Within 2 d after attachment, OLGs extended processes and began to express an outward current that represents a composite response of an inactivating/transient component and a noninactivating component. The current had a reversal potential of $-66 \mathrm{mV}$ and was sensitive to potassium channel blockers. After 4-5 $d$ in culture, the transient component was less prominent, often accompanied by an increase in noninactivating or steady-state outward current. In addition, there was an increase in inward rectifier current. Four of 7 cells that failed to develop processes exhibited only linear high-resistance membranes. We conclude that cultured OLGs express 3 voltage-gated potassium conductances: (1) a transient outward current, (2) a noninactivating outward current, and (3) an inward rectifier current. The sequential appearance of the several currents may relate, at least in part, to process formation.
\end{abstract}

Oligodendrocytes (OLGs) play a critical role in nervous system function. Circumstantial evidence suggests that following an inducing signal of unknown type, and in a burst of activity, they form myelin; thereafter, they maintain it. OLGs are capable of remyelinating CNS axons after a demyelinating injury, implying regenerative plasticity and a capacity to respond a second time to a putative myelin-inducing signal. Whether the inducing signals need to be provided by axons is uncertain. Recent work by Szuchet and coworkers (Szuchet et al., 1983; Yim et al., 1986; Vartanian et al., 1986) suggests that, at least for cultured OLGs, interaction with a polylysine substratum suffices to stimulate OLGs to reexpress a myelinogenic metabolism and to reform myelin in culture in the absence of neurons, of axons, or of other cell types (Szuchet et al., 1986). This cultured OLG system affords a good model for seeking out a relationship between the signal for myelin synthesis and ionic current modulation.

Whereas there is evidence that OLGs influence the complementary distribution of voltage-sensitive ionic channels in the

\footnotetext{
Received July 16, 1987; revised Oct. 5, 1987; accepted Oct. 8, 1987.

This work was supported by MS Society Grants RG-1130-E-18 to B.G.W.A. and RG-1223-C4 to S.S., by NIH Grant GM-36823 to D.J.N. and by a gift from the Lucille P. Markey Charitable Trust. We wish to thank Drs. P. Shrager for advice in the initial stages of the project and $\mathrm{H}$. Fozzard for careful review of the manuscript. We would also like to thank M. Lang for technical assistance in the isolation of oligodendrocytes.

Correspondence should be addressed to Deborah J. Nelson, Ph.D., Department of Neurology, Box 425, The University of Chicago, 5841 South Maryland Avenue,
} Chicago, IL 60637.

Copyright $\odot 1988$ Society for Neuroscience $0270-6474 / 88 / 062131-11 \$ 02.00 / 0$ myelinated axon, i.e., $\mathrm{Na}^{+}$channels clustered at the nodes of Ranvier, and $\mathrm{K}^{+}$channels distributed along the internodal zone (Waxman, 1987), little is known about the functional role played by ion channel of OLGs themselves. It was suggested that they may participate in $\mathrm{K}^{+}$homeostasis (Kuffler and Nicholls, 1966; Gardner-Medwin, 1981). Kettenmann et al. (1982) demonstrated a channel in isolated membrane patches from embryonic mouse spinal cord OLGs that was highly sclcctive for $\mathrm{K}^{+}$, with a conductance of $71 \pm 34 \mathrm{pS}$. In their subsequent studies (Kettenmann et al., 1984a), they observed a small but consistent effect of depolarization, which increased channel open state probability at membrane potentials between -90 to $-30 \mathrm{mV}$. In contrast, no voltage-dependent conductances were observed when OLGs from rat optic nerve were depolarized to $+20 \mathrm{mV}$ using whole-cell recording techniques (Bevan and Rafr, 1985).

The goal of this study was to identify and characterize the whole-cell currents of OLGs at different stages in culture as part of an attempt to investigate the relationship between ionic current modulation and myelin reformation. In contrast to earlier reported studies, we have found that cultured OLGs do express a voltage-dependent outward current that has an inactivating/ transient component and a noninactivating or steady-state component. In addition, these cells develop an inward rectifier current after a weck in culture. The magnitudes of the noninactivating component of outward current and the inward rectifier current increase with time in culture.

\section{Materials and Methods}

Cell culture. OLGs were isolated from the brains of 4- to 6-month-old lambs as described previously. Freshly isolated cells, band III (see Szuchet et al., 1980, for details) were plated on plastic culture plates at $2 \times$ $10^{6}$ cells $/ \mathrm{ml}$. Approximately $40 \%$ of the cells attached to the plate; the remaining cells formed small floating clusters. The latter are referred to as B3·f OLG (Szuchet and Yim, 1984). After 4-5 d, the supernatant containing B3.f OLG was collected and centrifuged. The cells in the pellet were resuspended in culture medium and replated into polylysinecoated petri dishes onto the surface of which the OLG attached. The latter cells are referred to as B3 fA (A for adherent). B3 fA OLG were maintained in Dulbecco's modified Eagles' medium supplemented with $20 \%$ horse serum, $2 \mathrm{~mm}$ glutamine, and antibiotic $(0.3 \mu \mathrm{g} / \mathrm{ml} \mathrm{Ampho-}$ tericin $\mathrm{B}$ and $2.4 \mu \mathrm{g} / \mathrm{ml}$ Garamycin). Cultures were fed twice weekly. Culture purity was ascertained to be $98-99 \%$ using a monoclonal antibody against galactocerebroside (a gift from Dr. B. Ranscht), as well as polyclonal antibody against $2^{\prime}, 3^{\prime}$-cyclic nucleotide $3^{\prime}$-phosphohydrolase (a gift from Dr. T. Sprinkle). Cells were tested 2-14 d after attachment.

Electrophysiology. Recordings were obtained using the whole-cell configuration of the patch-clamp technique as described by Hamill et al. (1981). A List EPC-7 patch-clamp amplifier (List Electronic, Darmstadt, Eberstadt, FRG) was used. The dish with the cultured cells was placed in a chamber on the movable stage of an inverted Leitz microscope 
Figure 1. Phase-contrast micrographs of live oligodendrocytes. Bar in $d$ represents $35.6 \mu \mathrm{m}$ for $a$ and $b ; 21.2 \mu \mathrm{m}$ for $c$ and $d$. $a, b$, Micrographs of cultured oligodendrocytes that have extended processes but do not make contact with the adjacent cells. Most of the measurements reported here were made on such cells. $c$, Cultured oligodendrocytes after $1 \mathrm{~d}$ of adherence. These cells have no processes. They have linear high-resistance membranes (see text). $d$, Cultured oligodendrocytes after $15 \mathrm{~d}$ in vitro. Cells form a complex network of interconnecting processes. Notice cell-cell apposition; tight junctions are formed between apposed cells.

Figure 2. Effect of the holding potential on OLG currents. Inactivation of the outward current but not of the inward current occurred when the holding potential was changed from -80 $\mathrm{mV}(A)$ to $-40 \mathrm{mV}(B)$. Pulses of 360 msec in duration at $10 \mathrm{sec}$ intervals were stepped to the following potentials (in $\mathrm{mV}):-50,-20,10,-100,-120,30$, $50,70,90,120$. $C$, Corresponding $I-V$ curve for both holding potentials constructed from the peak currents measured approximately 4-8 msec following the initiation of the pulses.
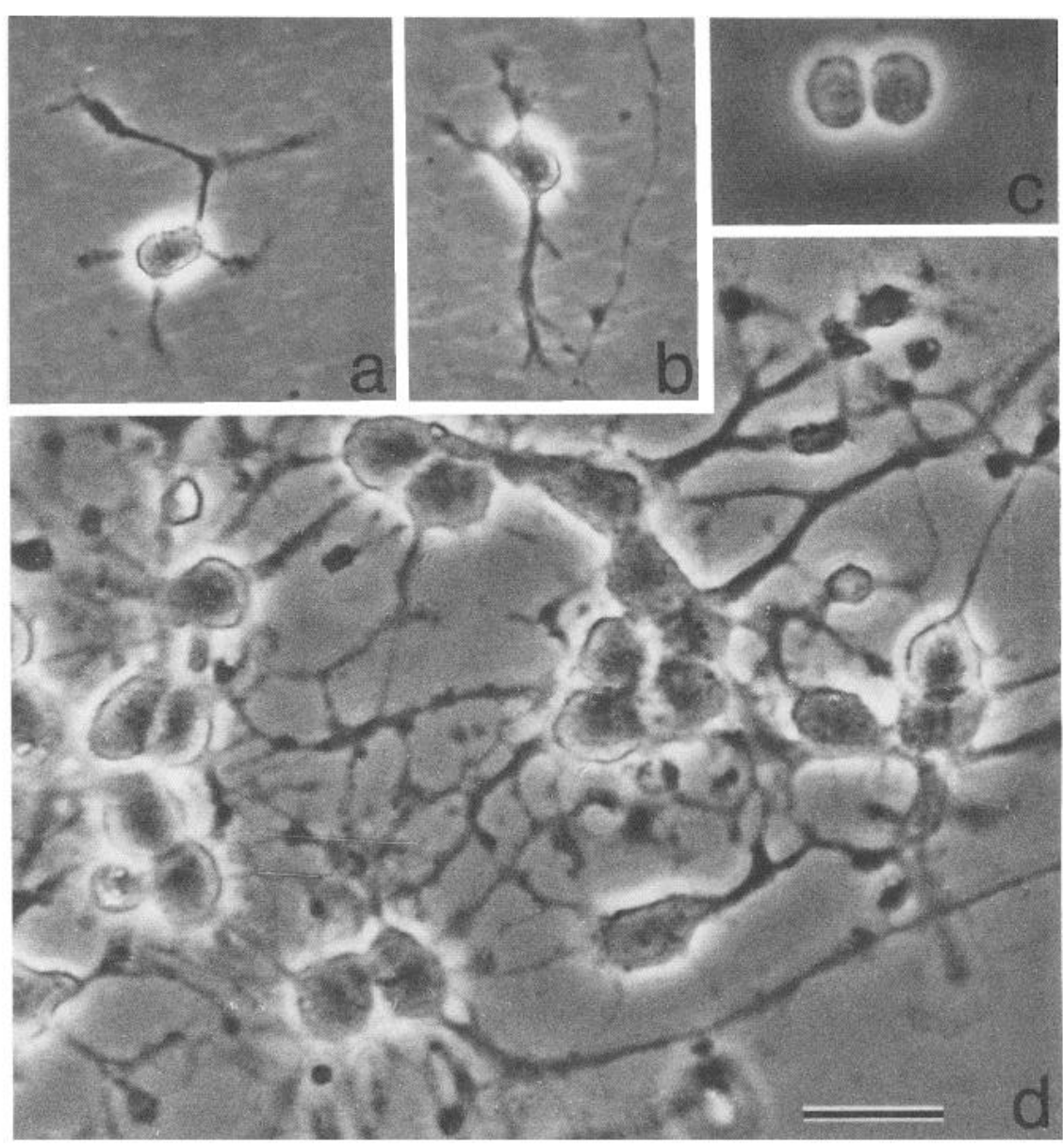

A

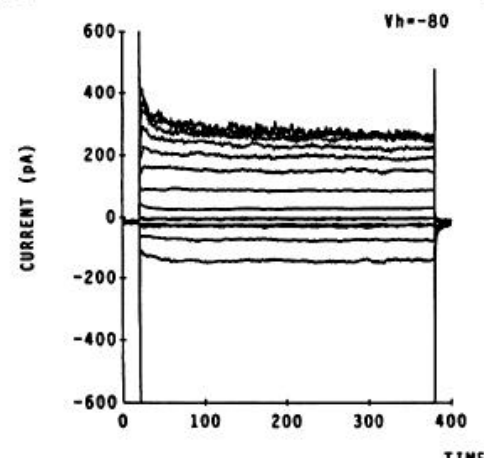

B



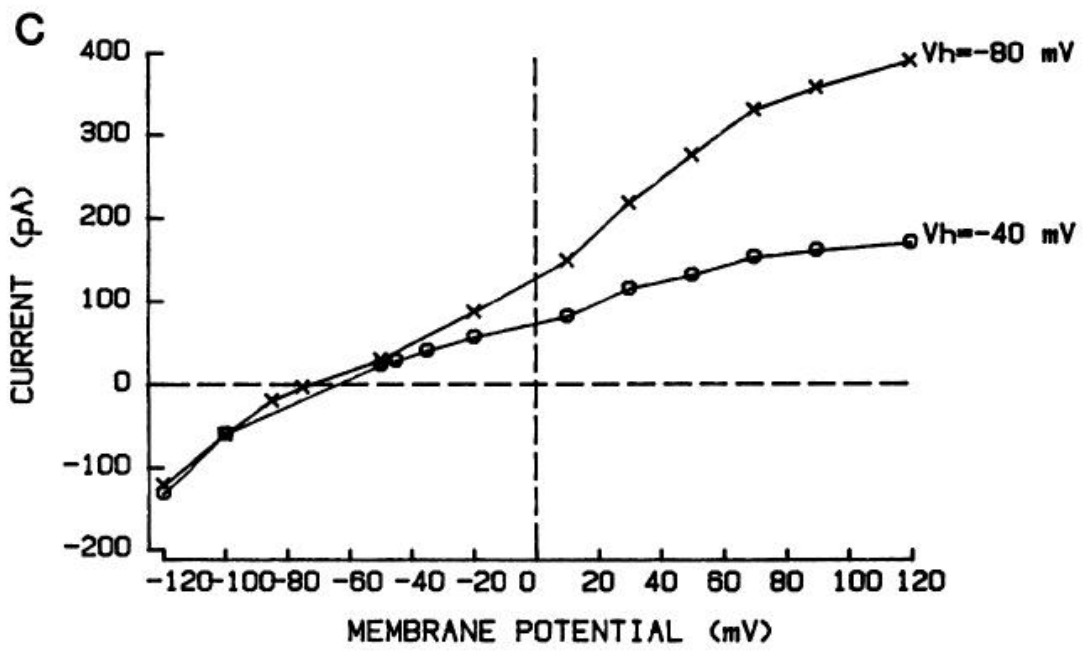


A
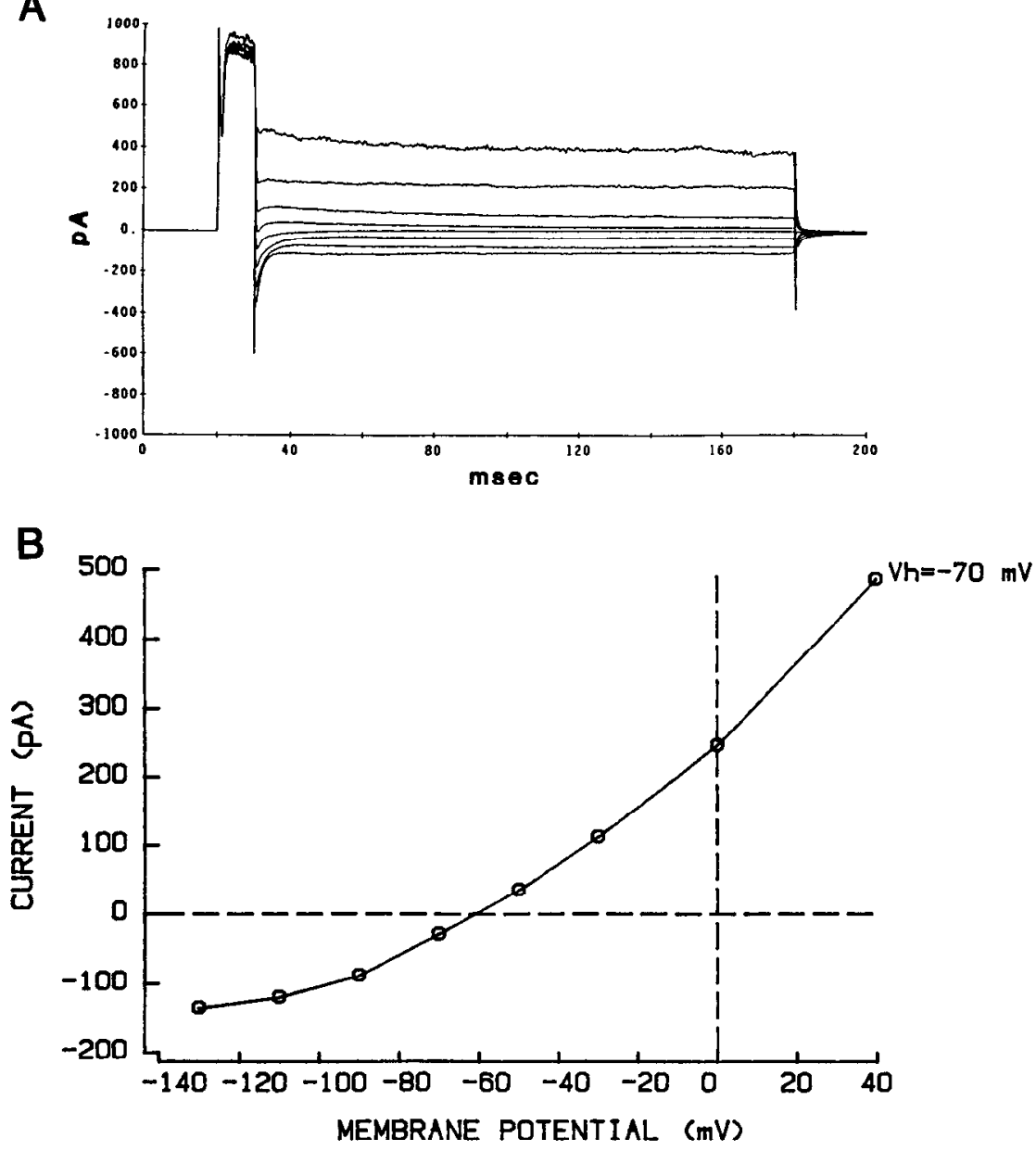

Figure 3. Deactivation of the transient outward current. $A$, Currents were elicited from a cell following depolarization to $120 \mathrm{mV}$ from a holding potential of $-70 \mathrm{mV}$ with subsequent rapid hyperpolarization to various potentials $(40,0,-30,-50,-70,-90$, $-110,-130 \mathrm{mV})$. Pulse interval duration was $60 \mathrm{sec} . B$, Corresponding $I-$ $V$ curve was constructed from the peak tail currents approximately 4-5 msec following the initiation of the voltage pulse. Current reversal was at approximately $-66.2 \mathrm{mV}$. equipped with phase-contrast optics. Recording pipettes were formed from soda lime glass (Blue-Dot Hematocrit Glass; Fisher Scientific Corp., Pittsburgh, PA) using a vertical puller in a 2-stage process. Pipettes were coated with Sylgard 184 (Dow-Corning, Midland, MI) and heat-polished to a final tip diameter of $0.5 \mu \mathrm{m}$ just before use. Cells were studied at room temperature. The bathing solution consisted of the following (in mM): $140 \mathrm{NaCl}, 5.4 \mathrm{KCl}, 2 \mathrm{CaCl}_{2}, 1 \mathrm{MgCl}_{2}, 10 \mathrm{HEPES} / \mathrm{NaOH}, \mathrm{pH}=$ 7.3. In some experiments, higher concentrations of $\mathrm{KCl}$ were used, in which case an equimolar amount of $\mathrm{NaCl}$ was replaced. Recording pipette (intracellular) solutions contained (in mM): $140 \mathrm{KCl}, 2 \mathrm{CaCl}_{2}, 2$ $\mathrm{MgCl}_{2}, 11$ EGTA, $10 \mathrm{HEPES} / \mathrm{KOH}, \mathrm{pH}=7.3$. External perfusion of the cells was performed in 2 ways: (1) by bringing a second pipette 20 $40 \mu \mathrm{m}$ from the voltage-clamped cell and applying puffs of a desired solution and (2) by exchanging the bath at a rate of $1 \mathrm{cc} / \mathrm{min}$. The voltage commands were provided via the output of a Metrabyte D/A converter and the data from the whole-cell recordings were sampled and analyzed using a Data Translation DT2818 A/D converter on an IBM-AT system. Unless specified, current records were filtered at $2 \mathrm{kHz}$ and sampled at $5 \mathrm{kHz}$. Data were not leak subtracted. Where multiple experiments were performed for a given experimental condition, the number of experiments is given in parenthesis. Values are reported as the mean \pm SEM, except when the number of experiments was less than 3 .

\section{Results}

\section{Resting membrane properties}

Whole-cell voltage-clamp studies were performed on cells that had been maintained in adherent culture for 2-14 $\mathrm{d}$ and whose cell bodies measured approximately $20-30 \mu \mathrm{m}$ in diameter (Fig. 1). Older cultures of OLGs form complex networks of interconnecting processes and were excluded from the study (Fig. 1d). OLGs in pure culture form tight junctions with one another, but they do not form gap junctions (Massa et al., 1984). They would, therefore, not be expected to be electrically coupled. However, Kettenmann et al. (1983a) were able to detect electrical coupling in 6 of 12 pairs of OLG between 50 and $100 \mu \mathrm{m}$ apart. For this reason, studies described in this investigation were confined to cells that had extended processes but had failed to make contact with adjacent cells (Fig. 1, $a, b$ ). In the few measurements performed on closely apposed cells, no obvious differences were observed in the ionic current expression. It should be noted that in vivo OLGs do form gap junctions with astrocytes though not between themselves.

The zero-current potential of cultured OLGs measured during the first few minutes after achieving the whole-cell recording conformation was $-68 \pm 3.3 \mathrm{mV}$ (15) as determined from current-voltage plots. We presume that the actual value of the

Table 1. Resting membrane properties of oligodendrocytes

\begin{tabular}{lll} 
Days & $\begin{array}{l}\text { Resting membrane } \\
\text { potential } \\
(\mathrm{mV})\end{array}$ & $\begin{array}{l}\text { Input resistance } \\
(\mathrm{G} \Omega)\end{array}$ \\
\hline $1-3 \quad(n=15)$ & $-68.1 \pm 3.31$ & $1.08 \pm 0.14$ \\
$4-7 \quad(n=8)$ & $-64.1 \pm 5.81$ & $0.57 \pm 0.15$ \\
$8-14(n=15)$ & $-66.8 \pm 3.01$ & $0.36 \pm 0.07$ \\
\hline
\end{tabular}




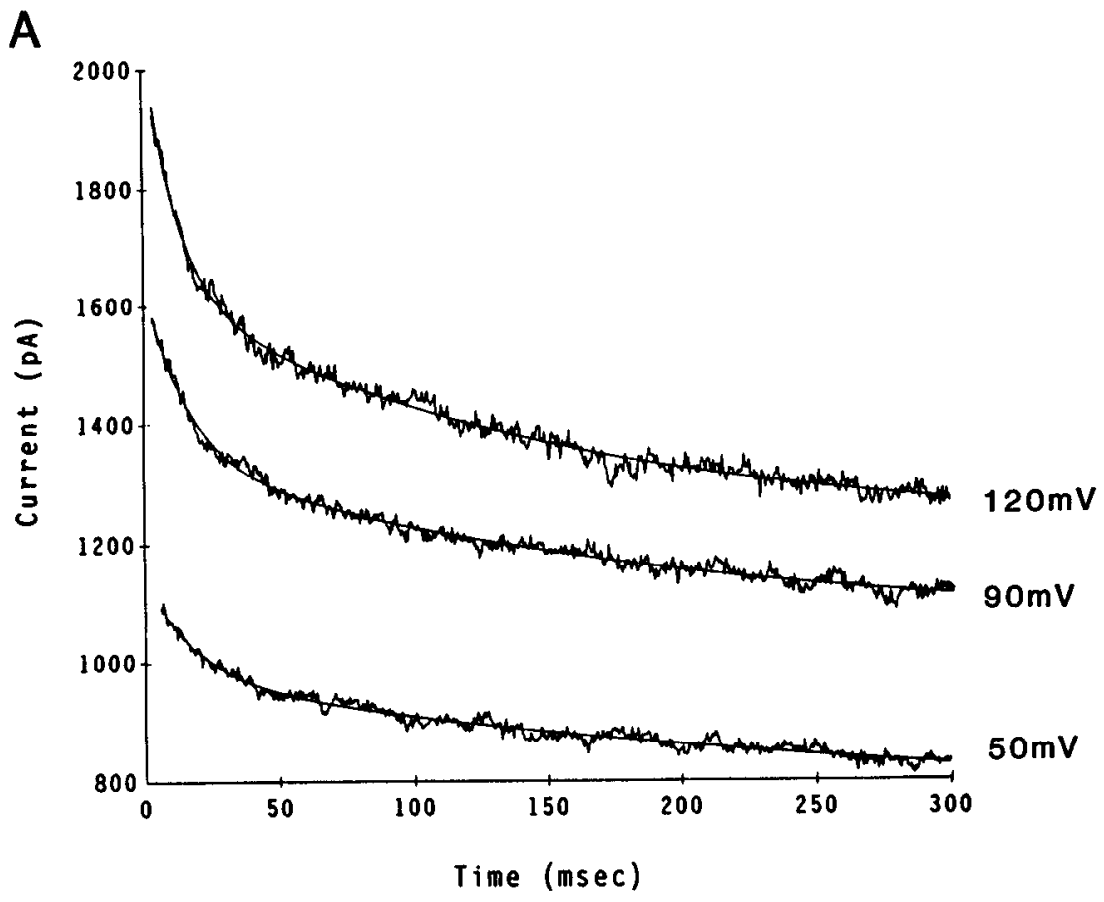

Figure 4. Time course of inactivation of the transient outward current. $A$, Exponential fit to the data points is superimposed on each current record. The pulse potential is indicated to the right of each trace. $B, C$, Voltage dependence of the fast $(B)$ and slow $(C)$ time constants obtained from the exponential fits to the decay phase of the currents in $A$.

B

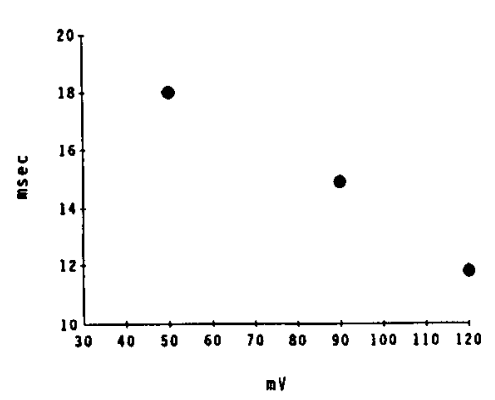

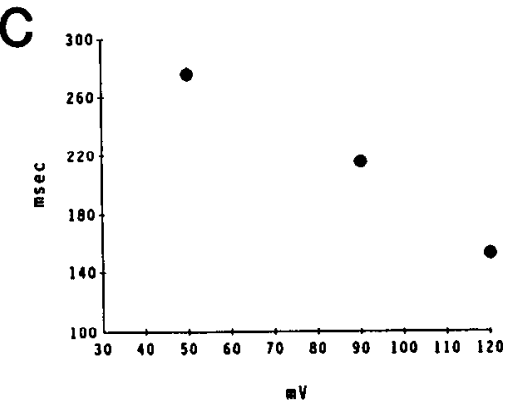

resting potential is negative to this value since any leak due to insufficient sealing of the patch electrode would reduce the amplitude of the zero-current potential to values less hyperpolarized than the resting potential. Input resistances determined as the reciprocal of the chord conductance measured between -100 to $-70 \mathrm{mV}$ was calculated to be $1.08 \pm 0.14 \mathrm{G} \Omega$ (15) during the first $3 \mathrm{~d}$ in adherent culture. Table 1 lists changes in membrane properties that were observed during development in adherent culture. While the resting membrane potential did not change significantly with time in culture, the input resistance decreased after $7-14 \mathrm{~d}$ to $0.36 \pm 0.07 \mathrm{G} \Omega(15)$, presumably correlated with process extension. An increase in the capacity transient was observed upon transition from cell-attached to whole-cell recording. Owing to the relatively small size of the cells, this increase was small and difficult to quantify. However, in 5 cells in which ionic currents were blocked by high concentrations of $\mathrm{Cs}^{+}$in the recording pipcttc, membranc capacitance was measured by integrating the current during a voltage step and subtracting a baseline established $10 \mathrm{msec}$ after the step. It ranged from $6.8 \mathrm{pF}(2)$ in cells without processes to $18.2 \mathrm{pF}$ (3) in cells with processes, corresponding to calculated diameters ranging from 14 to $28 \mu \mathrm{m}$. Using these values and assuming that the membrane capacitance is $1 \mu \mathrm{F} / \mathrm{cm}^{2}$, the calculated specific membrane resistance would be $5-7 \mathrm{~K} \Omega \mathrm{cm}^{2}$. This value is very similar to that found by Kettenmann et al. (1984b).

\section{Whole-cell currents}

Positive voltage pulses from the holding potential $(-80 \mathrm{mV})$ activated a voltage- and time-dependent outward current in cultured OLGs. Whole-cell voltage-clamp records from an OLG after $4 \mathrm{~d}$ in adherent culture can be seen in Figure 2. The transient component of the current was inactivated at the depolarized holding potential of $-40 \mathrm{mV}$, leaving a steady-state component of variable amplitude (Fig. $2 B$ ). Figure $2 C$ shows the peak current-voltage relationship for the currents depicted in Figure 2, $A$ and $B$. In general, the current-voltage relation for the transient or peak current remained constant with time after the establishment of the whole-cell configuration, allowing 3-5 min for initial stabilization.

The ionic selectivity of the transient component of the outward current was determined from the reversal of the tail currents in the presence of $5.4 \mathrm{~mm}$ external $\mathrm{K}^{+}$. The membrane potential was first changed to $120 \mathrm{mV}$ for $10 \mathrm{msec}$ (Fig. 3A) and then stepped back to various test potentials. The instantaneous current voltage relationship ( $5 \mathrm{msec}$ following the onset of the tail currents) indicates that the reversal potential was $-66.2 \pm$ $1.45 \mathrm{mV}(4)$. The calculated reversal potential for perfectly $\mathrm{K}^{+}$selective channels is $-82 \mathrm{mV}$. Increasing the $[\mathrm{K}]_{0}$ from 5.4 to $35 \mathrm{mM} \mathrm{K}^{+}$shifted the reversal potential to $-19.8 \mathrm{mV}(2)$, giving the predicted relative shift of $47 \mathrm{mV}$ expected in the reversal 

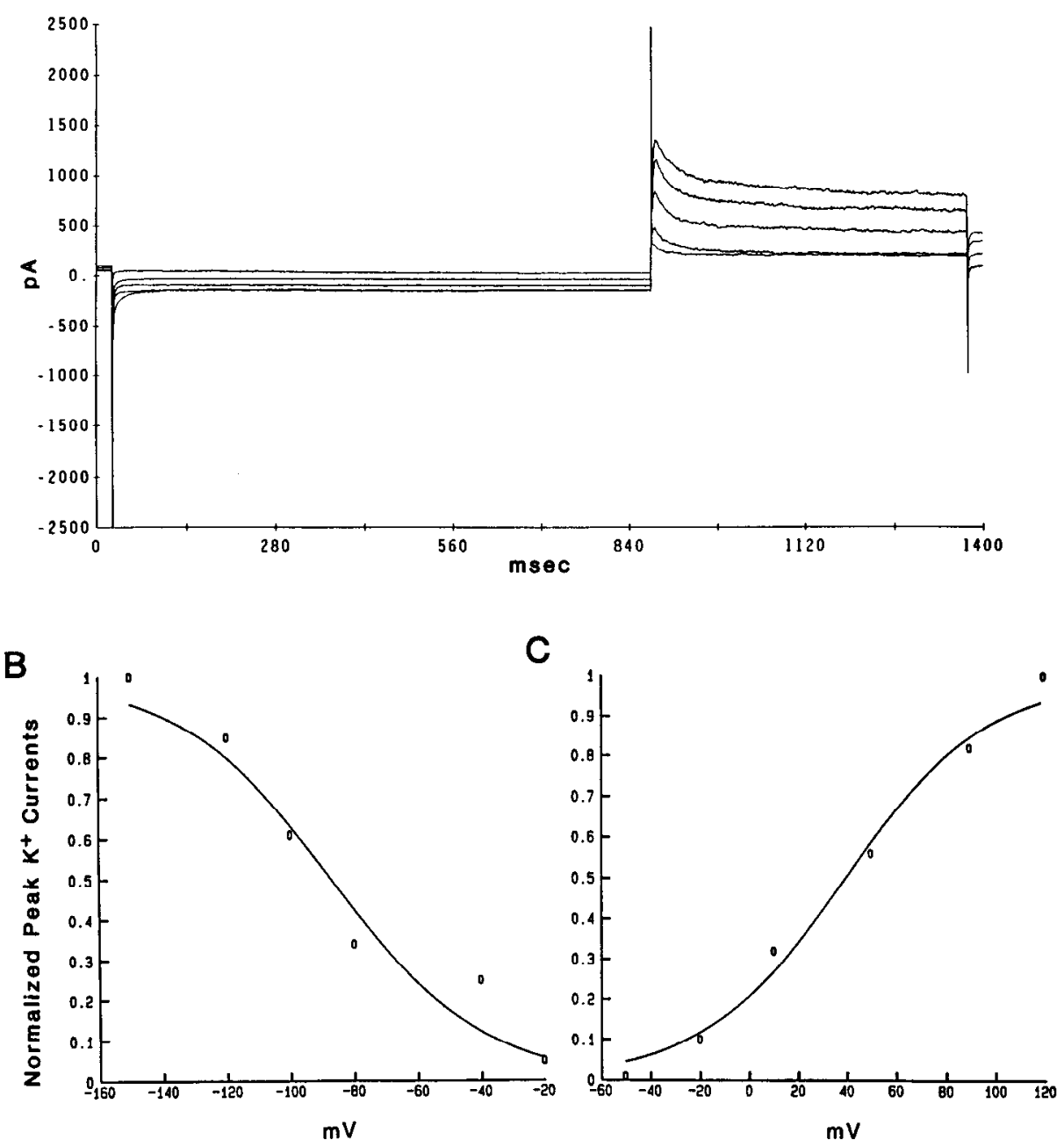

Figure 5. Inactivation and activation of the transient outward current. $A$, Current records from a cell $(3 \mathrm{~d}$ in adherent culture), which was maintained at a holding potential of $-20 \mathrm{mV}$, and depolarized to $+40 \mathrm{mV}$ following 850 msec prepulses to various hyperpolarized potentials $(-40,-60,-80,-100$ $-120,-150 \mathrm{mV}$ ). Pulse interval duration was $60 \mathrm{sec}$. Similar results were obtained when a $1.4 \mathrm{sec}$ prepulse was used. $B$ and $C$, Steady-state parameters of inactivation $(B)$ and of activation $(C)$ for the current data normalized to the maximal current obtained ( $n=5$ for both activation and inactivation data). The normalized currents were fitted using the Boltzmann function: $\mathbf{j}=\mathrm{I}_{\mathrm{K} \text { max }} /$ $\left.\left\{1+\exp \left[\left(V-V_{f}\right) / K_{f}\right)\right]\right\}$, where $V_{f}$ is the midpoint and $K_{f}$ the slope factor. For the illustrated inactivation data: $V_{f}=$ $-87.16 \mathrm{mV}, K_{f}=23.8$; for the activation data, $V_{f}=39.5 \mathrm{mV}, K_{f}=-29.6$. of the tail current. In view of the above, it seems reasonable to conclude that the current is carried predominantly by $\mathrm{K}^{+}$.

The time course of inactivation of the transient outward current could be reasonably described by first-order kinetics with the time constant of current decay decreasing as membrane potential became more positive (Fig. 4 ). The decay phase at 120 $\mathrm{mV}$ was best fitted by a single exponential in 10 cells (mean = $48.4 \pm 7.02 \mathrm{msec}$ ) and best fitted by a double exponential in 27 cells $\left(\tau_{1}=10.3 \pm 0.94 \mathrm{msec} ; \tau_{2}=122.2 \pm 19.7 \mathrm{msec}\right)$. Interestingly, the frequency polygon of $\tau_{1}$ in these 27 cells revealed a bimodal distribution, with the earlier peak at $4 \mathrm{msec}$ and a later pcak at $14.4 \mathrm{mscc}$. The mean time to peak of the current at $120 \mathrm{mV}$ was $3.9 \pm 2.7 \mathrm{msec}$ (37). Currents recorded in the cells bathed in a $\mathrm{Ca}^{2+}$-free medium displayed no significant change in their kinetics. In a few experiments where leak current was subtracted, the time course of activation and inactivation was not significantly different before and after subtraction.

The voltage dependence of the steady-state availability of the transient component of the outward current was studied by recording the peak current at a constant depolarized potential following prepulses to various hyperpolarized potentials. The normalized peak currents were fitted using a Boltzmann function of the form

$$
j=I_{K, \max } /\left\{1+\exp \left[\left(V-V_{f}\right) / K_{f}\right]\right\}
$$

allowing the midpoint $V_{f}$ and the slope factor $K_{f}$ to vary. An example can be seen in Figure 5. The average midpoint of inactivation from similar fits of data from 5 cells was $-87.56 \pm$ $3.59 \mathrm{mV}$, with a slope factor of $21.1 \pm 2.42$. Data from the current-voltage relationships obtained with the same cells were also normalized and fitted with the same Boltzmann function to obtain steady-state parameters of activation. The average midpoint for activation was $35.4 \pm 4.0 \mathrm{mV}$, with a slope factor of $-25.6 \pm 3.08$.

The complex nature of the outward current was investigated pharmacologically. The transient component of the outward current was blocked by 4-aminopyridine (4-AP) (Fig. 6). The amplitude of the peak transient current was reduced by $54 \%$ at $120 \mathrm{mV}$ with a low concentration of externally applied 4-AP $(0.25 \mathrm{~mm})$. At $2.5 \mathrm{~mm}$ 4-AP, only the steady-state component of the outward current remained, which had a reversal potential of $-48.4 \mathrm{mV}$ as determined from the tail currents. Therefore, the steady-state current is not a nonspecific leak current and would appear to be predominantly carried by $\mathrm{K}^{+}$ions. In some records, the steady-state current bears resemblance to the delayed rectifier current of nerve and muscle.

Both the transient component and the steady-state component of the outward current were reduced by externally applied tetraethylammonium (TEA; $4 \mathrm{~mm}$ ). Internal $\mathrm{Cs}^{+}$(110 mM) blocked the outward current completely (data not shown). At lower con- 
A

Figure 6. Effect of 4-AP on OLG currents. Currents obtained from a cell prior to $(A)$ and after $(B)$ exposure to 4-AP. The pulse protocol was as described in Figure 1. The holding potential was -80 mV. 4-AP (2.5 mM) was applied via a second pipette brought adjacent to the voltage-clamped cell. $C$, Corresponding $I-V$ curves prior to and following exposure to 4-AP were constructed from the peak currents as described in Figure 1 .

C

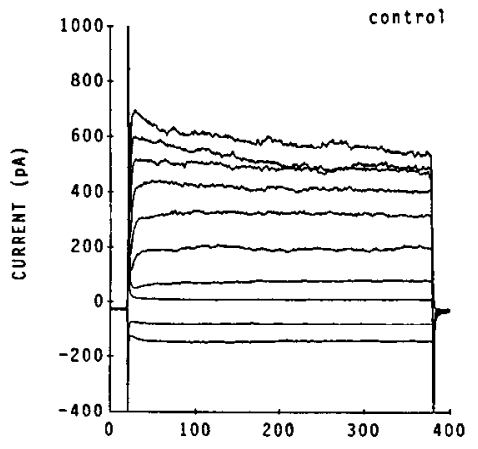

B
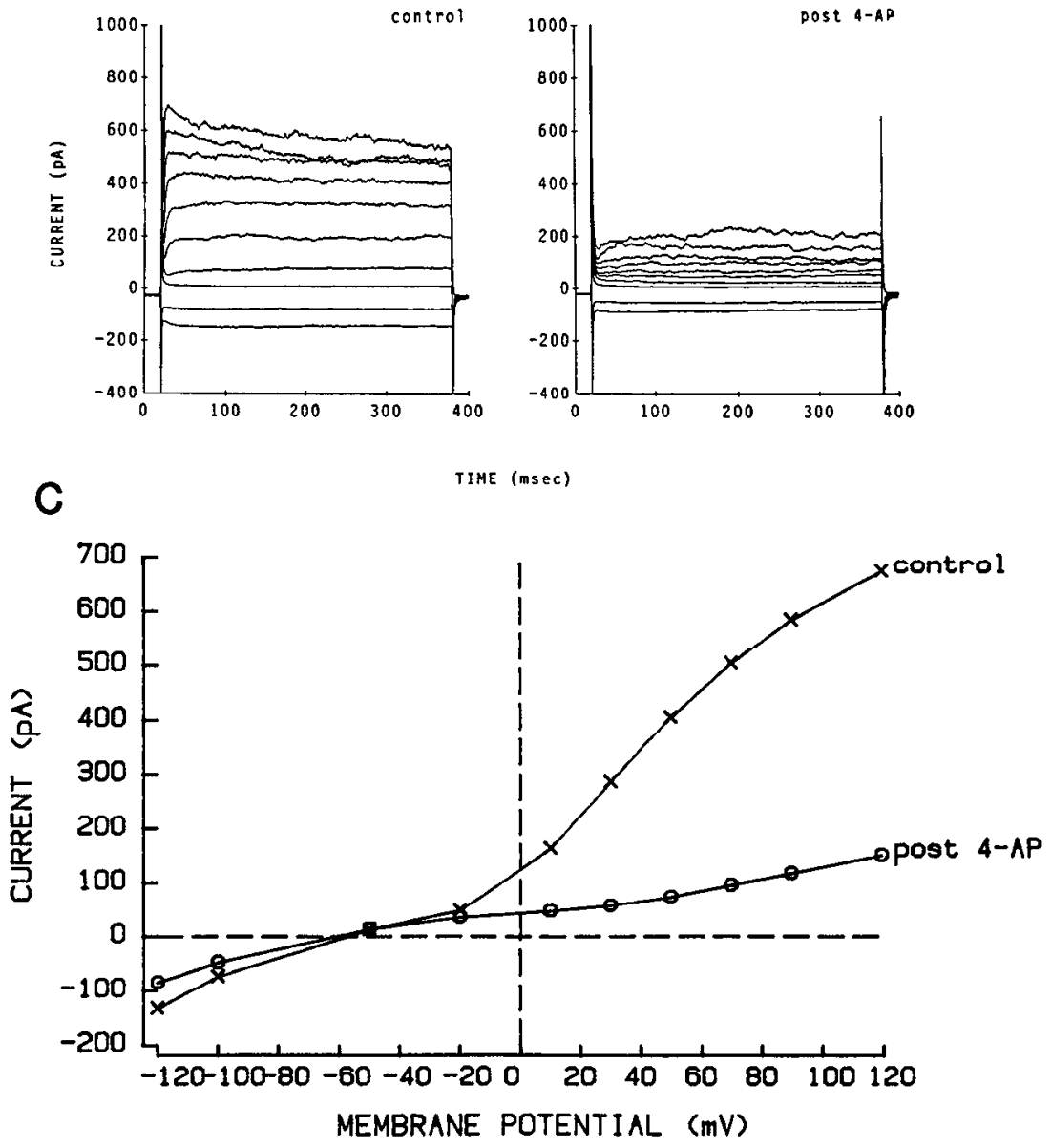

ccntrations of external TEA $(0.5 \mathrm{~mm})$ or internal $\mathrm{Cs}^{+}(10 \mathrm{mM})$, the steady-state component of the outward current was reduced to a greater extent than the transient component. The steadystate current was not reduced significantly by $1 \mathrm{~mm}$ external $\mathrm{Cd}^{2+}$, nor was it enhanced by exposure to the calcium ionophore A23187.

Inward current activation was observed in the hyperpolarized voltage range $(-100$ to $-120 \mathrm{mV})$. This current is similar to the inward rectifier of other cell types. Strong inward rectification with instantaneous and time-dependent components can be seen in Figure 7, which shows the currents evoked when the potential was stepped from a holding potential of $-20 \mathrm{mV}$ to different potentials between 120 to $-150 \mathrm{mV}$. The time-dependent increase in the $\mathrm{K}$ conductance followed first-order kinetics, with the time constant of the activation phase decreasing as the voltage pulses became more negative. For the currents shown in Figure 7 , the activation phase time constant decreased from $27.2 \mathrm{msec}$ at $-100 \mathrm{mV}$ to $3.8 \mathrm{msec}$ at $-150 \mathrm{mV}$, a 7 -fold reduction. Inactivation of this current upon strong hyperpolarization was nearly abolished when the $\mathrm{Na}^{+}$concentration in the bath was decreased.

Changing the $[\mathrm{K}]_{0}$ from 5.4 to $70 \mathrm{mM} \mathrm{K}^{+}$increased the amplitude of the inward current. The conductance measured at $-150 \mathrm{mV}$ was $7.86 \mathrm{nS}$ in high-K solution, whereas the conductance was $3.2 \mathrm{nS}$ in normal Ringers' solution. The reversal potential in the high- $\mathrm{K}^{+}$solutions shifted by $53 \mathrm{mV}$ to a more depolarized potential. In addition, the rate of activation was increased while the amount of inactivation was decreased. The amplitude of this current at strong hyperpolarizations was substantially reduced, and the time course of inactivation accelerated considerably when the pipette solution was replaced by $\mathrm{CsCl}(110 \mathrm{~mm})$. Figure 8 illustrates the sensitivity of the inward current to $\mathrm{BaCl}_{2}$ (100 mM). Suppression of this current was also observed when only $1 \mathrm{mM} \mathrm{BaCl}_{2}$ was used.

\section{$O L G$ currents as a function of age in culture}

Evidence supporting the observations that the voltage-activated outward current is composed of more than one conductance comes from the studies of OLG currents at different times in culture. Within $48 \mathrm{hr}$ of plating, B3.fA OLG began to develop processes and express voltage-gated outward currents. After 1 week in culture, the transient component of the outward current appeared reduced. This reduction was often accompanied by an increase in the steady-state or noninactivating component of the outward current. In addition, there was an increase in inward rectifier current as shown in Figure 9 . In a series of 85 experiments, we found that $88 \%(30 / 34)$ of cells with processes after day 7 of adherent culture developed inward rectifier compared with $18 \%(5 / 28)$ of cells at days $1-3$ and $26 \%(6 / 23)$ at days 4 7. The difference in the frequency of inward rectifier in cells before day 7 and after day 7 in adherent culture was highly significant $\left(p<0.001\right.$ as determined by $\chi^{2}$ analysis). Interestingly, $57 \%(4 / 7)$ of those few cells that remained without processes after 2 weeks in culture exhibited linear high-resistance membranes (Fig. 10). The other 3 cells showed current patterns similar to the cells with processes, including inward rectifier. 
A
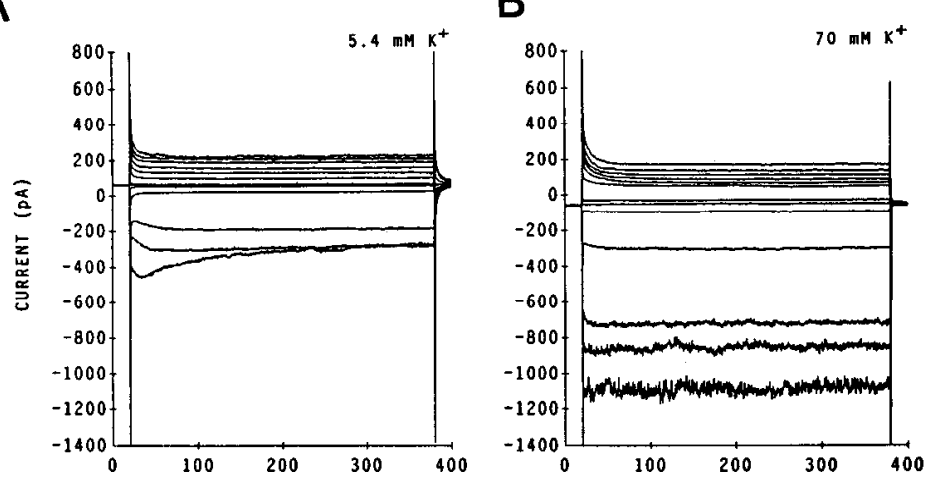

TIME (msec)

C

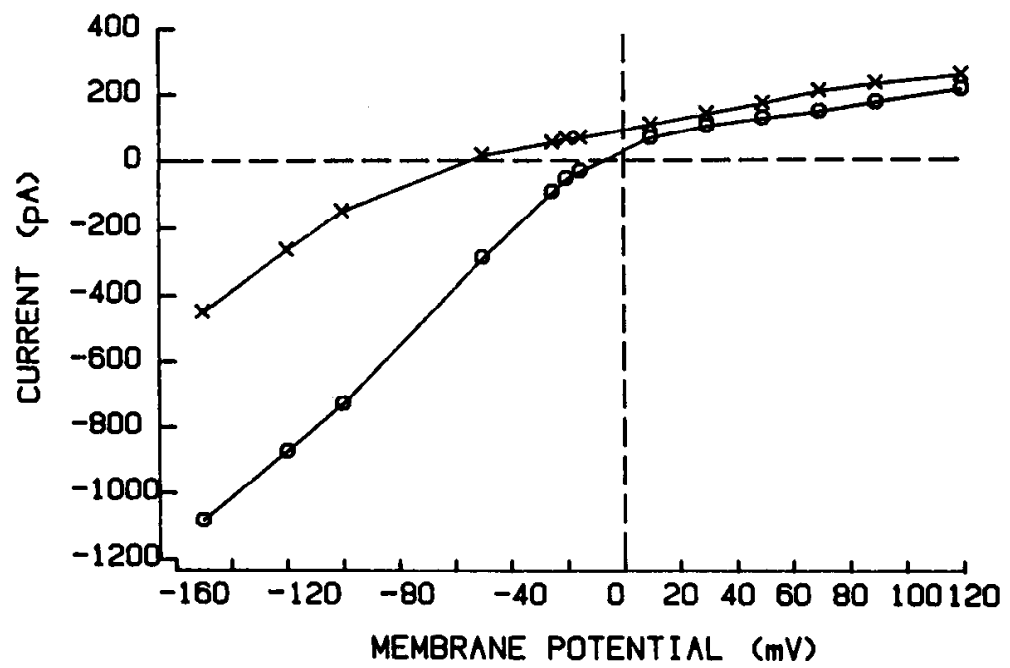

A

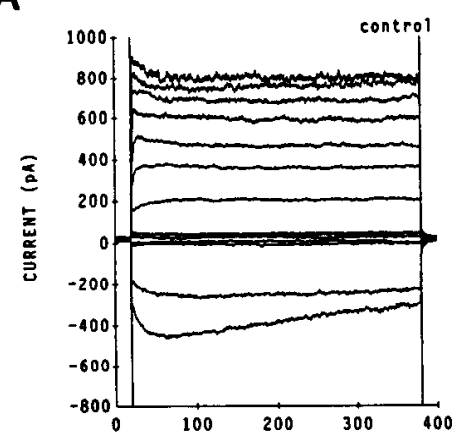

B

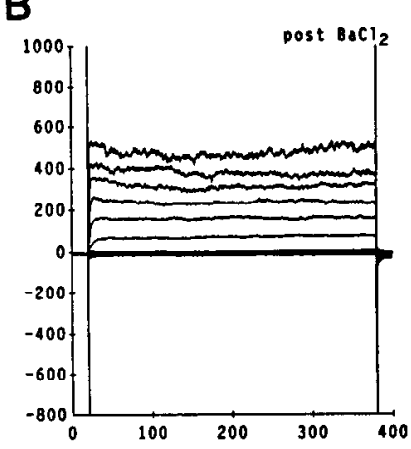

C

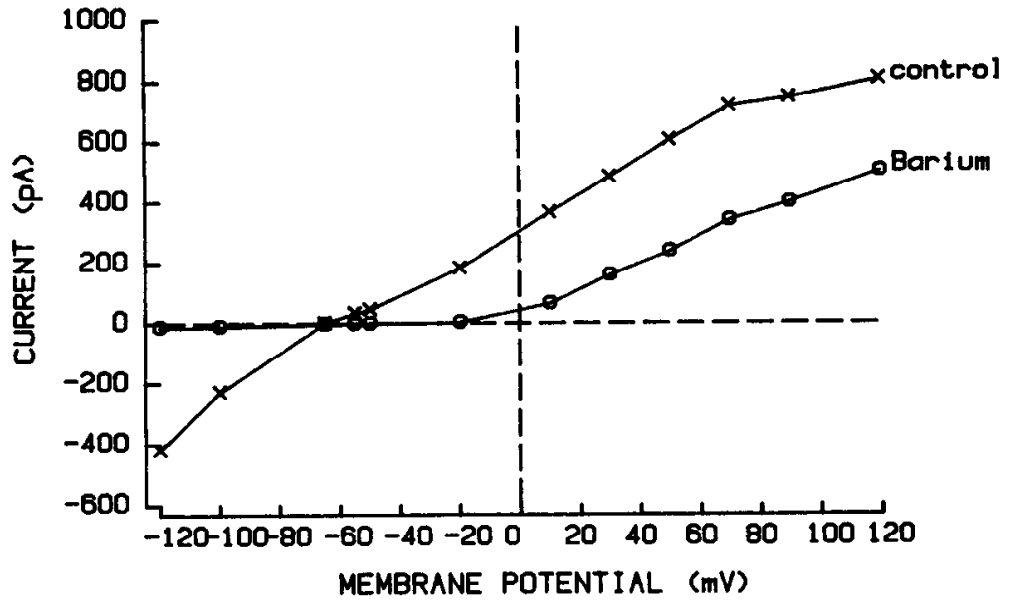

Figure 7. Effect of $[\mathrm{K}]_{0}$ on inward rectifier. Currents displayed in $A$ and $B$ were from the same cell voltage-clamped at a holding potential of $-20 \mathrm{mV}$ where the external bathing solution contained the $\mathrm{K}^{+}$concentration noted in each panel. The pulse protocol was as described in Figure 1. C, Corresponding $I-V$ curves at 5.4 (crosses) and $70 \mathrm{~mm}$ (open circles) external $\mathrm{K}^{+}$showing the strong dependence of the inward current on the external $\mathrm{K}^{+}$concentration.

Figure 8. Effect of $\mathrm{BaCl}_{2}$ on inward rectifier. $A, B$, Currents obtained from the same cell before and after the microperfusion of $\mathrm{BaCl}_{2}(100 \mathrm{~mm})$ onto the voltage-clamped cell. Pulse protocol was as described in Figure 1, $V_{h}=$ $-80 \mathrm{mV}$. $C$, Corresponding $I-V$ curve for the currents depicted in $A$ and $B$. 
A
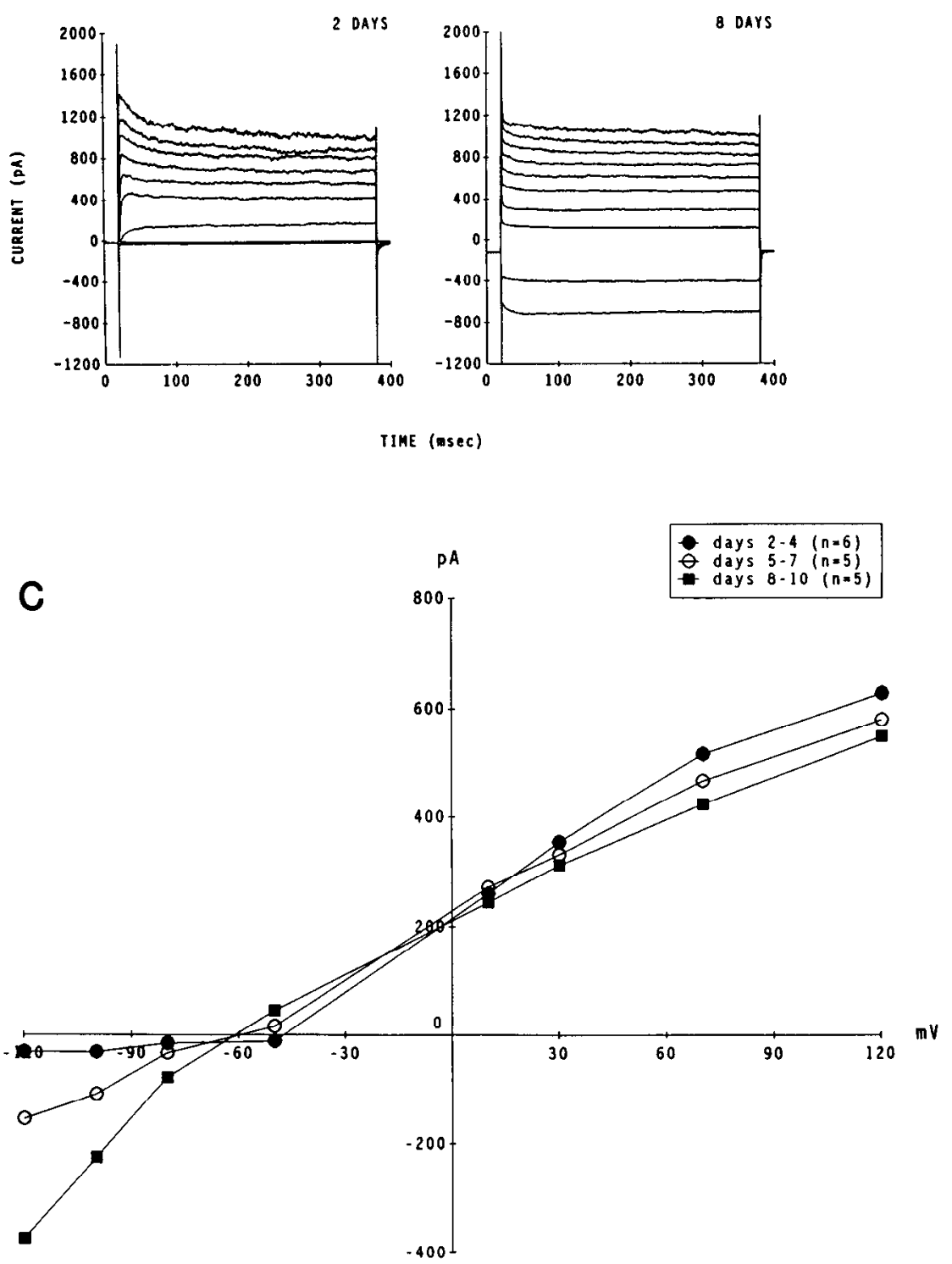

\section{B}

.4001
Figure 9. OLG currents as a function of age in culture. An increase in inward current and a decrease in the transient component of the outward current were observed in OLG after 1 week in culture. Illustrated current records are from cells cultured from the same cell preparation. Pulse protocol was as described in Figure $1, V_{h}=-80 \mathrm{mV}$. Data in $C$ were averaged from 5-6 experiments for each developmental period $(2-4,5$ 7 , and $8-10 \mathrm{~d}$ )
The cells without processes were identified as OLGs by antigalactocerebroside staining.

\section{Discussion}

The electrophysiological properties of OLGs were examined with the whole-cell configuration of the patch-electrode voltageclamp technique. The experiments in this study demonstrate the existence of a voltage-dependent outward current and an inward rectifier current that are $\mathrm{K}^{+}$selective. The voltage-gated outward current most likely represents a composite response of 2 separate conductances. This contrasts with the reports by Bevan and Raff (1985) and Bevan et al. (1986), who did not find voltage-dependent conductances in OLGs. Kettenmann et al. (1984a) did observe a small voltage-dependence in their singlechannel studies of OLGs (average change in $P_{\circ}$ was $0.08 \pm 0.04$ per $10 \mathrm{mV}$ step). We were unable to demonstrate a role for $\mathrm{Ca}^{2+}$ in activating the $\mathrm{K}^{+}$currents since (1) the calcium current blocker cadmium had no effect (Brown and Griffith, 1983; Galvan and Sedlmeir, 1984; Beluzzi et al., 1985b), and (2) there was no observable increase in current amplitude following exposure of the cells to calcium ionophore A23187 in calcium-containing bathing solution.

The potassium outward current was characterized by voltagedependent activation and inactivation. This current resembles the $\mathrm{K}^{+}$current identified as the delayed rectifier type in lymphocytes (DeCoursey et al., 1984) and astrocytes (Bevan and Raff, 1985; Bevan et al., 1986) differing in the time course of current inactivation and the degree of voltage dependence. It should be noted that inactivation was not described for the delayed rectifier by Hodgkin and Huxley (1952) but was subsequently found to be present in delayed rectifier currents of various cell types (Nakajima, 1966; Connor and Stevens, 1971b). The time constant of the decay phase was on the order of hundreds of milliseconds in lymphocytes (DeCoursey et al., 1984), whereas, in OLGs, it was approximately $10 \mathrm{msec}$ for the rapidly inactivating component and $120 \mathrm{msec}$ for the slowly inactivating component. That the potassium outward current may be a composite response of the 2 separate conductances was supported by the change in current profiles with time in culture and its differential sensitivity to various potassium blockers. A low 
A

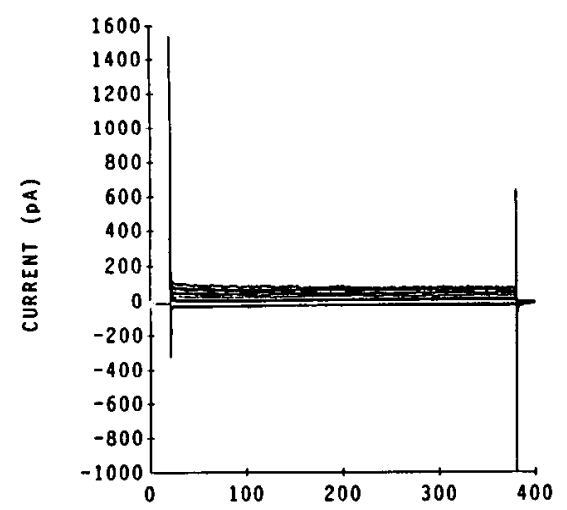

B

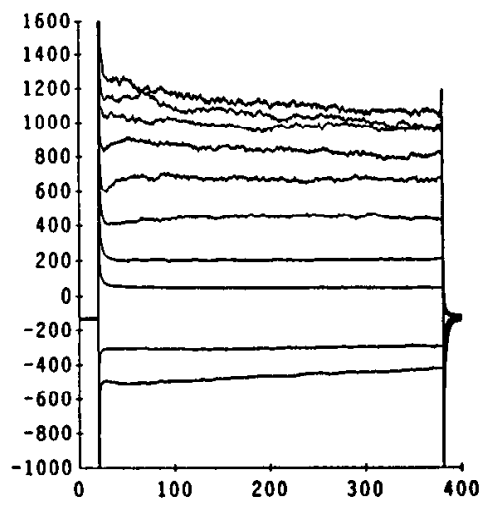

C

IIME (msec)

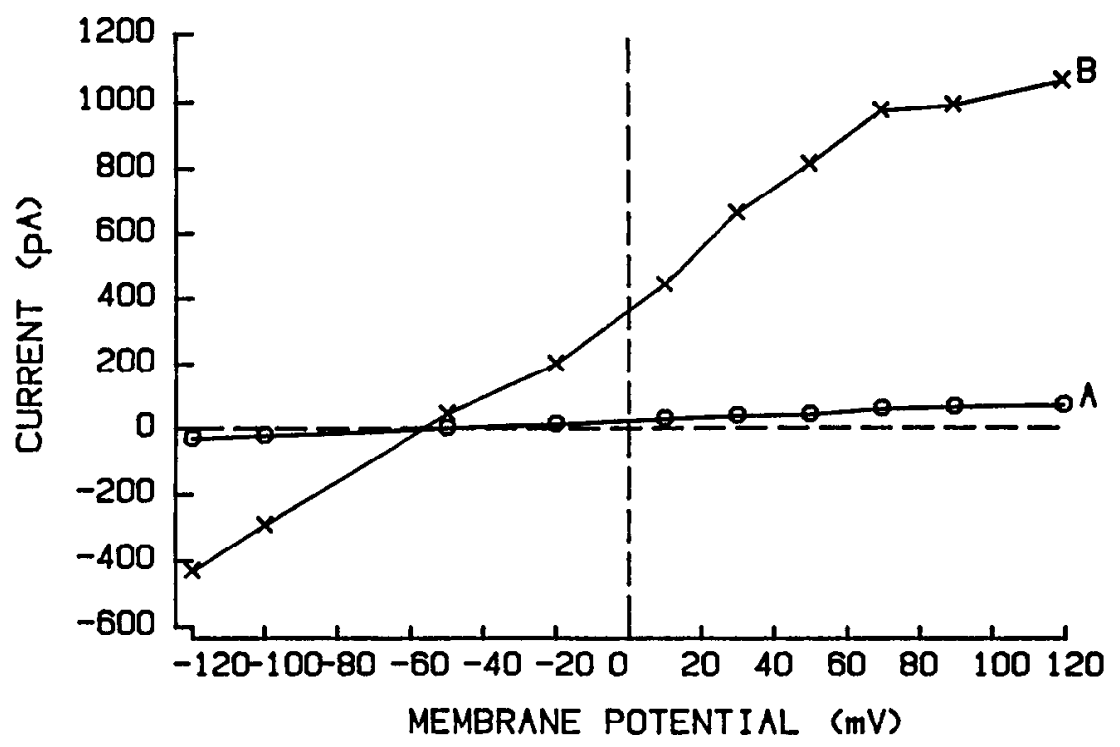

Figure 10. Comparison of currents obtained from 2 separate cells with and without processes. Four out of the seven cells tested that remained without processes after 2 weeks in culture exhibited linear high-resistance membranes. Pulse protocol was as described in Figure $1, V_{h}=-80 \mathrm{mV} . A$, Current trace from a cell without processes. $B$, Current trace from a cell with processes. $C$, Current-voltage relationship for the 2 cells depicted in $A$ and $B$.

concentration of externally applied 4-AP $(0.25-1 \mathrm{mM})$ preferentially suppressed the transient component of the outward current, while low concentration of external TEA $(0.5 \mathrm{~mm})$ or of internal $\mathrm{Cs}^{+}(10 \mathrm{~mm})$ preferentially reduced the steady-state outward current. Higher concentrations of these agents block both currents completely. Similar findings with regard to inactivating and noninactivating $\mathrm{K}^{+}$currents have been described in astrocytes (Bevan and Raff, 1985; Nowak et al., 1987). In previous studies in OLGs, Kettenmann et al. (1982, 1984a) observed that externally applied TEA (10 mM) did not affect the specific membrane resistance of OLGs as measured with intracellular electrodes, nor did it affect the single potassium channel conductance or kinetics using inside-out patches. The discrepancy between their results and ours is uncertain, but it may be related in part to the different source and age of cultured OLGs studied. Most of the work of Kettenmann et al. (1982, 1984a, b) involved 4- to 6-week-old cultures of OLGs isolated from embryonic mouse spinal cord, whereas our OLGs were isolated from the white matter of lamb brains and were used after 2-14 $d$ in adherent culture.

The transient component of the outward current resembles $I_{\mathrm{A}}$ in neurons (Galvan and Sedlmeir, 1984; Beluzzi et al., 1985a) in that it is markedly reduced when the holding potential is changed from -80 to $-40 \mathrm{mV}$. It is also extremely sensitive to 4-AP. However, the steady-state parameters of activation and inactivation differ somewhat from the transient outward currents observed in neurons (Galvan and Sedlmeir, 1984; Beluzzi et al., 1985a) or in cardiac muscle cells (Fozzard and Hiraoka, 1973; Kenyon and Gibbons, 1979). Activation threshold occurs at -20 to $+10 \mathrm{mV}$, with the midpoint at $+35.4 \mathrm{mV}$ and with a slope factor of 25.6. The midpoint of inactivation is slightly more hyperpolarized $(-87.5 \mathrm{mV})$ than in sympathetic neurons (Galvan and Sedlmeir, 1984; Beluzzi et al., 1985a) with a less steep slope. The transient outward current is ubiquitous in excitable cells (Rogawski, 1985) and seems to play an important role in neuronal frequency encoding (Connor and Stevens, 1971a) and in action potential repolarization, particularly in cardiac muscle cells (Kenyon and Gibbons, 1979). Its function in nonexcitable cells such as OLGs is less clear. The bimodal distribution of $\tau_{1}$ describing current decay is intriguing. It is possible that the OLG population may be heterogeneous, even though most of our cells were of the interfascicular type.

After 1 week in culture, the transient component of the outward current appeared reduced, with an increase in steadystate outward current. Linearization of the current-voltage relationship may be explained partly on the basis of process 
extension by Cole's theorem (Cole and Curtis, 1941). However, at approximately the same time, there was an increase in inward current. The inward current in OLGs behaved similarly to the inward rectifier described in other cell types (Hagiwara et al., 1976; Standen and Stanfield, 1978; Hagiwara and Yoshii, 1979; Stanfield et al., 1985). The activation of this conductance depended on voltage as well as external potassium concentration and was blocked by barium. As expected, the input resistance of cells kept in culture for more than $7 \mathrm{~d}$ from the time of plating was lower than that of cells examined at earlier times since most of the older cells expressed inward rectifier current. Interestingly, the resting membrane potential did not differ significantly with time in culture. That the inward rectifier appears later than potassium outward current is not surprising since developmental changes in ionic currents have been demonstrated to follow a defined sequence in many cells (Salkoff and Wyman, 1983; Blair and Dionne, 1985; Nerbonne el al., 1986). For example, transient outward current is the first voltage-activated current to appear in Drosophila flight muscles (Salkoff and Wyman, 1983), while it appears 4-6 d later than the delayed rectifier in rat embryonic superior cervical ganglion cells (Nerbonne et al., 1986). The functional significance of such a sequence of developmental changes in ionic current expression in OLGs remains an intriguing question and may well be associated with the basis for the development of myelinogenic signal transduction in these cells.

While exclusive potassium dependence of resting membrane potential in OLGs has been demonstrated (Kettenmann, 1983b), we were unable to find significant changes in resting membrane potential with time in culture that corresponded to the change in current patterns. Another interesting finding in our study is that 4 of 7 cells that remained without processes at late times in culture exhibited linear high-resistance membranes. While no definite conclusion can be drawn, the finding is interesting since endfeet of retinal glial cells have been reported to have higher densities of potassium channels than the cell body (Newman, 1984; Brew et al., 1986). A nonuniform distribution of potassium conductance has also been demonstrated in optic nerve astrocytes (Newman, 1985).

In summary, we have identified voltage-dependent potassium conductances in cultured OLGs, an outward current and an inward rectifier current. We propose that the outward current is a composite response of a transient component and a noninactivating or steady-state component. We were unable to observe macroscopic $\mathrm{Ca}$ or Na currents that have been described in other glial cells such as astrocytes (MacVicar, 1984; Bevan et al., 1986) and Schwann cells (Gray et al., 1986). We observed that the outward current appeared earlier in culture than the inward rectifier current. The appearance of the currents may depend in part on process formation. We postulate that, as in neuronal preparations, OLG currents may be physiologically modulated by transmitters or hormones affecting cellular function.

\section{References}

Beluzzi, O., O. Sacchi, and E. Wanke (1985a) A fast transient outward current in the rat sympathetic neurone studied under voltage-clamp conditions. J. Physiol. (Lond.) 358: 91-108.

Beluzzi, O., O. Sacchi, and E. Wanke (1985b) Identification of delayed potassium and calcium currents in the rat sympathetic neurone under voltage clamp. J. Physiol. (Lond.) 358: 109-129.

Bevan, S., and M. Raff (1985) Voltage-dependent potassium currents in cultured astrocytes. Nature 315: 229-232.

Bevan, S., S. Y. Chiu, P. T. A. Gray, and J. M. Ritchie (1986) Voltage- gated ion channels in rat cultured astrocytes. In J. M. Ritchie, R. D. Keynes, and L. Bolis, eds., Ion Channels in Neural Membranes, pp. 159-174, Liss, New York.

Blair, L. A., and V. E. Dionne (1985) Developmental acquisition of calcium sensitivity by $\mathrm{K}^{+}$channels in spinal neurones. Nature 315 : 329-331.

Brew, H., P. T. A. Gray, P. Mobbs, and D. Attwell (1986) Endfeet of retinal glial cells have higher densities of ion channels that mediate $\mathrm{K}^{+}$buffering. Nature 324: 466-468.

Brown, D. A., and W. H. Griffith (1983) Calcium-activated outward current in voltage-clamped hippocampal neurones of the guinea pig. J. Physiol. (Lond.) 337: 287-301.

Cole, K. S., and H. J. Curtis (1941) Membrane potential of the squid giant axon during current flow. J. Gen. Physiol. 24: 551-563.

Connor, J. A., and C. F. Stevens (1971a) Prediction of repetitive firing behavior from voltage clamp data on isolated neural somata under voltage clamp. J. Physiol. (Lond.) 213: 31-53.

Connor, J. A., and C. F. Stevens (1971b) Inward and delayed outward membrane currents in isolated neural somata under voltage clamp. J. Physiol. (Lond.) 213:1-19.

DeCoursey, T. E., K. G. Chandy, S. Gupta, and M. D. Cahalan (1984) Voltage-gated $\mathrm{K}^{+}$channels in human T-lymphocytes: A role in mitogenesis? Nature 307: 465-468

Fozzard, H. A., and M. Hiraoka (1973) The positive dynamic current and its inactivation properties in cardiac Purkinje fibres. J. Physiol. (Lond.) 234: 569-586.

Galvan, M., and C. Sedlmeir (1984) Outward currents in voltageclamped rat sympathetic neurones. J. Physiol. (Lond.) 356: 115-133.

Gardner-Medwin, A. (1981) Possible roles of vertebrate neuroglia in potassium dynamics, spreading depression and migraine. J. Exp. Biol. 95: 111-127.

Gray, P. T. A., S. Bevan, S. Y. Chiu, P. Shrager, and J. M. Ritchie (1986) Ionic conductances in mammalian Schwann cells. In Ion Channels in Neural Membranes, J. M. Ritchie, R. D. Keynes, L. Bolis, eds., pp. 145-157, Liss, New York.

Hagiwara, S., and M. Yoshii (1979) Effects of internal potassium and sodium on the anomalous rectification of the starfish egg as examined by internal perfusion. J. Physiol. (Lond.) 292: 251-265.

Hagiwara, S., S. Miyazaki, and P. Rosenthal (1976) Potassium current and the effect of cesium on this current during anomalous rectification of the egg cell membrane of a starfish. J. Gen. Physiol. 67: 621-638.

Hamill, O. P., A. Marty, E. Neher, B. Sakmann, and F. J. Sigworth (1981) Improved patch-clamp technique for high resolution current recording from cells and cell-free membrane patches. Pfluegers Arch. 391: 85-100.

Hodgkin, A. L., and A. F. Huxley (1952) A quantitative description of membrane current and its application to conduction and excitation in nerve. J. Physiol. (Lond.) 117: 500-544.

Kenyon, J. L., and W. R. Gibbons (1979) 4-Aminopyridine and the early outward current of sheep cardiac Purkinje fibers. J. Gen. Physiol. 73: 139-157.

Kettenmann, H., R. K. Orkand, H. D. Lux, and M. Schachner (1982) Single potassium channel currents in cultured mouse oligodendrocytes. Neurosci. Lett. 32: 41-46.

Kettenmann, H., R. K. Orkand, and M. Schachner (1983a) Coupling among identified cells in mammalian nervous system cultures. J. Neurosci. 3: 506-516.

Kettenmann, H., U. Sonnhof, and M. Schachner (1983b) Exclusive potassium dependence of membrane potential in cultured mouse oligodendrocytes. J. Neurosci. 3: 500-505.

Kettenmann, H., R. K. Orkand, and H. D. Lux (1984a) Some properties of single potassium channels in cultured oligodendrocytes. Pfluegers Arch. 400: 215-221.

Kettenmann, H., U. Sonnhof, H. Camerer, S. Kuhlmann, R. K. Orkand, and $M$. Schachner (1984b) Electrical properties of oligodendrocytes in culture. Pfluegers Arch. 401: 324-332.

Kuffler, S. W., and J. G. Nicholls (1966) The physiology of neuroglial cells. Ergebn. Physiol. 57: 1-90.

MacVicar, B. A. (1984) Voltage-dependent calcium channels in glial cells. Science 226: 1345-1347.

Massa, P. T., S. Szuchet, and E. Mugnaini (1984) Cell-cell interactions of isolated and cultured oligodendrocytes: Formation of linear occluding junctions and expression of peculiar intramembranous particles. J. Neurosci. 4: 3128-3139.

Nakajima, S. (1966) Analysis of $\mathrm{K}$ inactivation and TEA action in the supra-medullary cells of puffer. J. Gen. Physiol. 49: 629-640. 
Nerbonne, J. M., A. M. Gurney, and H. B. Rayburn (1986) Development of fast transient outward current in embryonic sympathetic neurones. Brain Res. 378: 197-202.

Newman, E. (1984) Regional specialization of retinal glial cell membrane. Nature 309: 155-157.

Newman, E. (1985) High potassium conductance in astrocyte endfeet. Science 233: 453-454.

Nowak, L., P. Ascher, and Y. Bernard-Netter (1987) Ionic channels in mouse astrocytes in culture. J. Neurosci. 7: 101-109.

Rogawski, M. A. (1985) The A current: How ubiquitous a feature of excitable cells is it? TINS 8: 214-219.

Salkoff, L., and R. Wyman (1983) Ion channels in Drosophila flight muscles. TINS 6: 128-133.

Standen, N. B., and P. R. Stanfield (1978) A potential and timedependent blockade of inward rectification in frog skeletal muscle fibers by barium and strontium. J. Physiol. (Lond.) 280: 169-191.

Stanfield, P. R., Y. Nakajima, and K. Yamaguchi (1985) Substance-P raises neuronal excitability by reducing inward rectification. Nature 315: 498-501.

Szuchet, S., and S. H. Yim (1984) Characterization of a subset of oligodendrocytes separated on the basis of selective adherene properties. J. Neurosci. Res. 11: 131-144.
Szuchet, S., B. G. W. Arnason, and P. E. Polak (1980) Separation of ovine oligodendrocytes into two distinct bands on a linear sucrose gradient. J. Neurosci. Methods 3: 7-9.

Szuchet, S., S. II. Yim, and S. Monsma (1983) Lipid metabolism of isolated oligodendrocytes maintained in long-term culture mimics events associated with myelinogenesis. Proc. Natl. Acad. Sci. USA 80: 7019-7023.

Szuchet, S., P. Polak, and S. H. Yim (1986) Mature oligodendrocytes cultured in the absence of neurons recapitulate the ontogenic development of myelin membranes. Dev. Neurosci. 8: 208-221.

Vartanian, T., S. Szuchet, G. Dawson, and A. Campagnoni (1986) Oligodendrocyte adhesion activates protein kinase C-mediated phosphorylation of myelin basic protein. Science 234: 1395-1398.

Waxman, S. G. (1987) Molecular organization of the cell membrane in normal and pathological axons: Relation to glial contact. In GlialNeuronal Communication in Development and Regeneration, $\mathrm{H}$. Althaus and W. Seifert, eds., pp. 710-736, Plenum, New York.

Yim, S. H., S. Szuchet, and P. E. Polak (1986) Culturcd oligodendrocytes. A role for cell-substratum interaction in phenotypic expression. J. Biol. Chem. 261: 11808-11815. 